\title{
Avaliação dos Componentes de Rendimento do Trigo quando Submetido a Diferentes Fontes de Nitrogênio
} Assessment of Wheat Yield When Subject to Various Sources of Nitrogen

\author{
Alexandre da Silveira Camponogara ${ }^{1}$, Gislayne Alves Oliveira² ${ }^{2}$ Jordana Georgin ${ }^{3}$ e Ana Lúcia \\ Denardin da Rosa ${ }^{4}$ \\ ${ }^{1}$ Pós-graduação em Engenharia de Processos/UFSM, Universidade Federal de Santa Maria, Santa Maria, RS, BR. \\ ${ }^{2}$ Pós-graduação em Engenharia Ambiental/UFSM, Universidade Federal de Santa Maria, Santa Maria, RS, BR. \\ ${ }^{3}$ Pós-graduação em Engenharia Ambiental/UFSM, Universidade Federal de Santa Maria, Santa Maria, RS, BR. \\ ${ }^{4}$ Pós-graduação em Engenharia Civil/UFSM, Universidade Federal de Santa Maria, Santa Maria, RS, BR.
}

\begin{abstract}
Resumo
Este estudo teve como objetivo avaliar os efeitos da aplicação de diferentes fontes de nitrogênio nos estados de emborrachamento e espigamento nos componentes de rendimento e na produtividade da cultura do trigo (Triticum aestivum L., Quartzo - OR Sementes). O experimento foi realizado em Frederico Westphalen-RS. O delineamento experimental utilizado foi de blocos completos ao acaso, com oito tratamentos e quatro repetições. Os tratamentos foram constituídos por combinações de diferentes fontes e formas de aplicação de $N$ que seguem: 11 - Testemunha (sem N na cobertura), T2 - Adubação de base + ureia, T3 - Adubação de base + nitrato de amônio, T4 - Adubação de base + ureia + nitrogênio foliar, T5 - Adubação de base + nitrato de amônio + nitrogênio foliar, T6 - Adubação de base + nitrogênio foliar, T7 - Adubação de base + ureia + nitrato de amônio e T8 - Adubação de base + nitrato amônio + ureia. A aplicação de nitrato de amônio associado com a suplementação de $N$ via foliar resultou em um acréscimo no rendimento de grãos de $51,5 \%$ em relação ao controle à testemunha. Demais componentes de rendimento também obtiveram médias com magnitudes significativas verificadas pelo teste de Duncan a $5 \%$ de probabilidade de erro.
\end{abstract}

Palavras-chave: Triticum aestivum. Adubação nitrogenada. Adubação foliar.

\begin{abstract}
This study aimed to evaluate the effects of applying different nitrogen sources in the states of booting and silking on yield components and the wheat crop productivity (Triticum aestivum L., Quartz - OR Seeds). The experiment was conducted in Frederico Westphalen-RS. The experimental design was a randomized complete block design, with eight treatments and four replications. The treatments consisted of combinations of different sources and forms of $N$ application that follow: T1 - control (no N), T2 - Fertilization base + urea, T3 - Basic fertilization + ammonium nitrate, T4 - Fertilizing base + urea + foliar nitrogen, T5 - Basic fertilization + ammonium nitrate + foliar nitrogen, T6 - Basic fertilization + foliar nitrogen, T7 - Basic fertilization + urea + ammonium nitrate and T8 - Basic fertilization + ammonium nitrate + urea. The ammonium nitrate application associated with the supplemental foliar $N$ resulted in an increase in grain yield of $51.5 \%$ over the control to the control. Other income components also obtained average with significant magnitudes verified by Duncan test at $5 \%$ error probability.
\end{abstract}

Keywords: Triticum aestivum. Nitrogen fertilizer. Foliar fertilization 


\section{Introdução}

O trigo (Triticum aestivum L.) é uma gramínea anual amplamente cultivada em todo mundo, com significativo peso na economia global. Atualmente, ocupa a segunda posição no cultivo entre os cereais, perdendo apenas para o milho. No Brasil, é cultivado nas regiões Sul, Sudeste e Centro-Oeste, destacando-se a Região Sul como responsável por 94\% da produção nacional (CONAB, 2012).

De acordo com Biudes e Camargo (2009), o melhoramento genético, associado às modernas práticas culturais, tem propiciado importantes avanços à cultura do trigo no Brasil. A obtenção de cultivares com características agronômicas de interesse que resultem em maior estabilidade e adaptabilidade às diferentes condições de cultivo tem resultado em significativos incrementos na produção de grãos.

Por outro lado, com a melhoria da qualidade genética da espécie, surgiram necessidades de um manejo mais criterioso para a cultura e, dentre outras práticas, pode-se citar a reformulação no manejo da adubação nitrogenada de cobertura como um dos principais responsáveis, juntamente com a genética, pelo aumento da produção de trigo no Brasil.

Atualmente, o consumo per capita de trigo no Brasil está em torno de $60 \mathrm{~kg}$, o que nos dá uma ideia da importância deste cereal não só para a economia do País, mas também como importante fonte de alimento para a população (EMBRAPA, 2011).

Quanto ao manejo da adubação na cultura, segundo Rosa Filho (2012), a disponibilidade de nitrogênio na planta durante o período de enchimento de grãos está diretamente relacionada com o percentual de proteína nos mesmos. O N é um dos nutrientes mais requeridos pelo trigo e, na maioria das vezes, não é oferecido na quantidade necessária e nem na época ideal para garantir rendimento e qualidade do produto final.

O manejo de adubações nitrogenadas é um dos mais complexos, devido a fatores relacionados ao custo dos fertilizantes nitrogenados decorrente de problemas na eficiência de algumas fontes (Menezes, 2004) e ao potencial poluente desse elemento, tanto para as águas superficiais quanto subterrâneas. Esse nutriente se caracteriza por possuir um dos maiores índices de perdas, as quais podem ocorrer por lixiviação, escorrimento superficial, erosão, volatilização de amônia e desnitrificação. O maior ou menor índice de perda pode ser contornado pela forma de aplicação, manejo e fonte do nutriente a ser utilizada (Queiroz et al., 2011).

A forma de aplicação do $\mathrm{N}$ pode influenciar o seu aproveitamento pelas plantas. A aplicação de ureia a lanço sobre o solo forma comumente usada pelos produtores na região dos Cerrados, devido à maior facilidade de aplicação e ao rendimento operacional, pode resultar em grandes perdas de $\mathrm{N}$, por volatilização de amônia (Cantarella, 1993) e danos foliares, podendo causar queima nas folhas (Yamada, 1996). Pode ocorrer, também, maior imobilização do $\mathrm{N}$ mineral pelos microrganismos quimiorganotróficos, para a decomposição dos resíduos vegetais presentes no solo (Silva et al., 2001).

Segundo Rosa Filho (2012), grande parte do nitrogênio utilizado pela planta na síntese de proteína é absorvida antes da floração, sendo que a quantidade deste nutriente armazenado nos tecidos é que definirá os teores de proteínas nos grãos.

Diante disso o presente estudo teve como objetivo avaliar o efeito da aplicação de diferentes fontes de nitrogênio nos estágios de emborrachamento e espigamento nos componentes de rendimento e na produtividade da cultura do trigo (Triticum aestivum L., Quartzo - OR Sementes).

\section{Material e Métodos}

\subsection{Caracterização da Área Experimental}

O trabalho foi conduzido em área experimental da Universidade Federal de Santa Maria, Campus

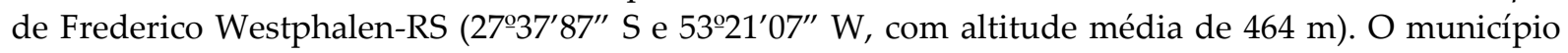
de Frederico Westphalen, pertence à Região Tritícola 2, caracterizando-se por ser moderadamente quente, úmida e baixa (EMBRAPA, 2009). Segundo a classificação de KÖEPPEN, o clima da região é 
do tipo Cfa - temperado chuvoso, com precipitação média anual elevada e bem distribuída ao longo do ano, sendo que a média anual fica em torno dos $1800 \mathrm{~mm}$, e subtropical do ponto de vista térmico (MORENO, 1961). Na região, predominam solos de textura argilosa, bem drenados, profundos a muito profundos, classificados como Latossolos Vermelhos Distróficos típicos. A área utilizada no experimento encontrava-se em pousio. Desta maneira, realizou-se dessecação total, 10 dias antes do estabelecimento da cultura, com herbicida Glyphosate em dosagem de $715 \mathrm{~g}$ de i.a. ha-1, mais uma aplicação do herbicida seletivo para o trigo Metsulfuron metílico em dosagem de $3.6 \mathrm{~g}$ de i.a. ha-1.

Para a implantação da cultura foi realizada a amostragem de solo da área experimental, um mês antes da semeadura do trigo, através do uso de pá-de-corte, segundo metodologia específica (COMISSÃO, 2004).

A amostra foi encaminhada para análise química no Laboratório de Solos da Universidade Regional Integrada do Alto Uruguai e das Missões (URI), campus de Frederico Westphalen e os resultados estão expressos na Tabela 1.

Tabela 1. Resultado da análise de solo realizada na área experimental por ocasião da instalação do experimento ${ }^{1}$. Frederico Westphalen - RS, 2011.

\begin{tabular}{|c|c|c|c|}
\hline Camada $(\mathrm{cm})$ & $0-20$ & Ca (Cmolc.L-1) & 6,4 \\
\hline Argila (\%) & 85 & $\operatorname{Mg}\left(\right.$ Cmolc.L $\left.L^{-1}\right)$ & 3,2 \\
\hline M.O. (\%) & 3,2 & $\mathrm{H}+\mathrm{Al}\left(\mathrm{Cmolc}^{-\mathrm{L}^{-1}}\right)$ & 5,5 \\
\hline $\mathrm{pH}\left(\mathrm{H}_{2} \mathrm{O}\right)$ & 5,7 & CTC (Cmolc.L L $\left.^{-1}\right)$ & 12,1 \\
\hline $\mathrm{SMP}\left(\mathrm{H}_{2} \mathrm{O}\right)$ & 6 & Al (Cmolc. $\left.\mathrm{L}^{-1}\right)$ & 0 \\
\hline$P\left(m L^{-1}\right)$ & 6,3 & V (\%) & 70,3 \\
\hline $\mathrm{K}\left(\mathrm{mg} \mathrm{L}^{-1}\right)$ & 172 & SatAl (\%) & 3,6 \\
\hline
\end{tabular}

${ }^{1}$ Dados obtidos a partir de análise de solo realizada no Laboratório de Análises de Solo e Tecido Vegetal da URI, Campus Frederico Westphalen.

\subsection{Implantação da cultura}

O preparo da área foi realizado em sistema Convencional de Semeadura, consistindo em aração profunda, seguida de duas gradagens. Optou-se por trabalhar com a cultivar de trigo Quartzo, da OR Sementes que apresenta as seguintes características agronômicas (Quadro 1).

Quadro 1. Características agronômicas da cultivar de trigo Quartzo1. Passo Fundo - RS, 2012.

\begin{tabular}{|l|l|r|r|l|}
\hline \multicolumn{7}{|c|}{ CARACTERÍSTICAS AGRONÔMICAS } \\
\hline Hábito vegetativo & Perfilhamento & Altura da planta $(\mathrm{cm})$ & PMS (mg) & Ciclo (dias) \\
\hline Intermediário a semi-ereto & Médio & 85 & 35 & Médio (120) \\
\hline
\end{tabular}

Realizou-se tratamento de sementes com inseticida Imidacloprido, em dosagem de 0,60 g de i.a. $\mathrm{kg}^{-1}$ de sementes, e com fungicida Triadimenol, com dosagem de 0,45 g de i.a. $\mathrm{kg}^{-1}$ de sementes.

Utilizou-se densidade de semeadura de 350 plantas $\mathrm{m}^{-2}$, com espaçamento entre linhas de $17 \mathrm{~cm}$ e profundidade de aproximadamente $3 \mathrm{~cm}$. A semeadura foi realizada no dia 20 de junho de 2011 de forma manual com auxílio de enxadas e de um rastel desenvolvido para demarcar o espaçamento das entre linhas.

A recomendação de adubação de base foi realizada seguindo critérios específicos, levando-se em consideração a análise química de solo e resultando em $400 \mathrm{~kg}^{\text {ha-1 }}$ de NPK na formulação 05-20-20 (COMISSÃ̃O, 2004). Foi efetuado o monitoramento de pragas, intervindo sempre que necessário, 
inserido neste contexto, realizaram-se três aplicações de fungicida, sendo nos estádios do alongamento, emborrachamento e enchimento de grãos, respectivamente.

\subsection{Fontes de nitrogênio utilizadas}

Como fontes de nitrogênio para adubação de cobertura foram utilizadas as seguintes fontes encontradas nos respectivos fertilizantes: Amídica - Ureia (45\% de N), Nítrica - Nitrato de Amônio (33,5\% de $\mathrm{N})$ e nítrico, amídico e amoniacal - N32 (32\% de N), sendo este último na forma liquida e fabricado pela empresa Ubyfol ${ }^{\circledR}$.

\subsection{Tratamentos}

Os tratamentos dimensionados para o experimento seguem: T1 - Testemunha (adubação de base), T2 - Adubação de base + adubação de cobertura (ureia), T3 - Adubação de base + adubação de cobertura (nitrato de amônio), T4 - Adubação de base + adubação de cobertura (ureia) + adubação foliar , T5 - Adubação de base + adubação de cobertura (nitrato de amônio) + adubação foliar, T6 Adubação de base + adubação foliar, T7 - Adubação de base + cobertura (ureia) + cobertura (nitrato de amônio) e T8 - Adubação de base + cobertura (nitrato amônio) + cobertura (ureia). As aplicações de N em cobertura foram feitas de acordo com a escala fenológica de Feeks e Large (Figura 1) no estádio 9 quando feita somente uma aplicação, e no estádio 10.1 quando feitas duas aplicações, esta numeração fenológica corresponde respectivamente ao pré - emborrachamento (lígula da última folha é visível), e início do espigamento (primeiras espigas recém visíveis).

Estas práticas foram realizadas baseando-se nas recomendações dadas aos produtores regionais de trigo (COODETC, 2010).

É importante frisar que quantidade de nitrogênio total utilizada para cada tratamento foi calculada de maneira que todos os tratamentos recebessem a mesma dosagem do nutriente (100 kg ha-1), exceto a testemunha que não recebeu aplicação de nitrogênio em cobertura, somente na base no momento da semeadura.

\subsection{Avaliações}

As avaliações procedidas visaram quantificar os principais componentes de rendimento da cultura do trigo. Os componentes avaliados foram: rendimento, número de afilhos por planta, número de espigas por metro quadrado e massa de mil grãos. Para a determinação do número de afilhos foram utilizadas 10 plantas por parcela, escolhidas ao acaso, no estádio do afilhamento, segundo a escala fenológica de Large e Feeks (1954), (Figura 1).

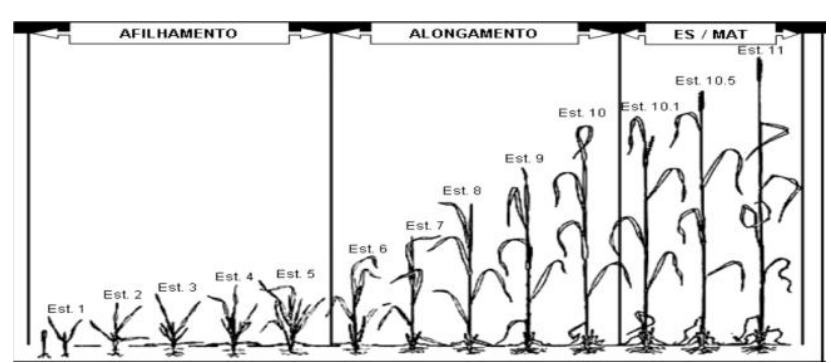

Figura 1. Estádios fenológicos da escala de Feeks e Large (1954).

Fonte: Feeks e Large (1954).

O componente número de espigas por metro quadrado foi obtido pela contagem do número de espigas em cada um dos dois pontos de amostragem $\left(0,25 \mathrm{~m}^{2}\right)$, sendo posteriormente extrapolado para metro quadrado. A massa de mil grãos foi obtida pela pesagem de oito sub-amostras de cem grãos, sendo extrapolada para massa de mil grãos, onde seguiu-se a metodologia específica (BRASIL, 2009). 
O peso de hectolitrico $(\mathrm{PH})$ foi calculado por meio da massa referente ao volume de $100 \mathrm{~L}$ de trigo, obtido por balança específica.

Para a avaliação da produtividade de grãos, coletaram-se manualmente dois pontos de 0,25 $\mathrm{m}^{2}(0,5$ $\mathrm{m} \times 0,5 \mathrm{~m}$ ), totalizando uma área de $0,5 \mathrm{~m}^{2}$, escolhidos ao acaso, para cada uma das parcelas. Foi efetuada a trilhagem manual das amostras, sendo posteriormente realizada a pesagem em balança eletrônica. Realizou-se a determinação da umidade, sendo posteriormente corrigida para $13 \%$.

Determinou-se a produção média da parcela pela média de produção de grãos obtida nos dois pontos coletadas por parcela.

\subsection{Delineamento experimental}

As parcelas foram dimensionadas, de forma que cada uma totalizasse oito metros quadrados (4 m x $2 \mathrm{~m}$ ). Para efeito das avaliações foram descartadas duas linhas laterais da parcela e $30 \mathrm{~cm}$ iniciais nas extremidades de cada linha a fim de diminuir o efeito de bordadura, desta forma, cada parcela teve uma área útil de 5,64 $\mathrm{m}^{2}$.

O delineamento experimental utilizado foi o de blocos completos casualizados (DBC), com quatro repetições para cada tratamento. Os resultados foram submetidos à análise de variância pelo teste F. Posteriormente realizou-se a comparação das médias para o fator fonte de adubação pelo teste de Duncan, ao nível de 5\%.

\section{Resultados e Discussão}

A análise de variância apresentou efeitos significativos na comparação dos tratamentos para as variáveis massa de mil sementes, produtividade $\left(\mathrm{kg} \mathrm{ha}^{-1}\right)$, peso hectolitrico, espigas $\mathrm{m}^{-2}$ e número de afilhos por planta. Os resultados médios estão apresentados nos Quadros 2 e 3.

Para a variável massa de mil sementes, houve diferença significativa entre os tratamentos, onde os tratamentos (adubação de base + nitrato de amônio + nitrogênio foliar), (adubação de base + ureia + nitrato de amônio) e (adubação de base + nitrato de amônio + ureia) apresentaram superioridade em relação aos demais para o caráter avaliado. Este é um dos componentes de rendimento que está diretamente relacionado com o rendimento final da cultura (BREDEMEIER et al. 2001).

Quadro 2. Resultados médios para as variáveis massa de mil grãos (MMS), produtividade (PROD) e peso hectolítrico (PH), Frederico Westphalen - RS, 2012.

\begin{tabular}{|c|c|c|c|}
\hline TRATAMENTOS** $^{*}$ & MMS(g) & PROD (kg ha-1) & PH \\
\hline 1 - Testemunha & $30,45 \mathrm{c}^{*}$ & $3178,80 \mathrm{~d}^{*}$ & $70,55 \mathrm{c}^{*}$ \\
\hline $2-\mathrm{AdB}+\mathrm{Ur}$ & $33,10 \mathrm{bc}$ & $64,34 \mathrm{~cd}$ & $76,05 \mathrm{~b}$ \\
\hline $3-\mathrm{AdB}+\mathrm{NA}$ & $33,78 \mathrm{ab}$ & $3860,40 \mathrm{~cd}$ & $78,3 \mathrm{ab}$ \\
\hline $4-\mathrm{AdB}+\mathrm{Ur}+\mathrm{NF}$ & $35,37 \mathrm{ab}$ & $4738,80 \mathrm{~b}$ & $78,15 \mathrm{ab}$ \\
\hline $5-\mathrm{AdB}+\mathrm{NA}+\mathrm{NF}$ & $37,40 \mathrm{a}$ & $6172,20 \mathrm{a}$ & $74,09 \mathrm{bc}$ \\
\hline $6-\mathrm{AdB}+\mathrm{NF}$ & $32,34 \mathrm{bc}$ & $3620,40 \mathrm{~cd}$ & $77,98 \mathrm{ab}$ \\
\hline $7-\mathrm{AdB}+\mathrm{Ur}+\mathrm{NA}$ & $36,04 \mathrm{a}$ & $5239,80 \mathrm{~b}$ & $79,09 \mathrm{a}$ \\
\hline $8-\mathrm{AdB}+\mathrm{NA}+\mathrm{Ur}$ & $36,79 \mathrm{a}$ & $5758,80 \mathrm{ab}$ & $80,69 \mathrm{a}$ \\
\hline $\mathrm{CV}(\%)$ & 3,32 & 15,08 & 3,97 \\
\hline
\end{tabular}

*Médias seguidas pela mesma letra na coluna não diferem estatisticamente pelo teste de Duncan ao nível de 5\% de probabilidade de erro. 
**AdB: adubação de base. Ur: uréia. NF: nitrogênio foliar. NA: nitrato de amônio.

Quadro 3. Resultados médios dos tratamentos para as variáveis número de espigas por metro quadrado (NE) e número de afilhos por planta (AP), Frederico Westphalen - RS, 2012.

\begin{tabular}{|c|c|c|}
\hline TRATAMENTOS & NE & AP \\
\hline $1-$ Testemunha & $350,5 \mathrm{e}^{*}$ & $2,04 \mathrm{~b}$ \\
\hline $2-\mathrm{AdB}+\mathrm{Ur}$ & $430,5 \mathrm{de}$ & $3,40 \mathrm{ab}$ \\
\hline $3-\mathrm{AdB}+\mathrm{NA}$ & $490,06 \mathrm{de}$ & $3,50 \mathrm{ab}$ \\
\hline $4-\mathrm{AdB}+\mathrm{Ur}+\mathrm{NF}^{* *}$ & $541,5 \mathrm{~cd}$ & $3,55 \mathrm{ab}$ \\
\hline $\begin{array}{c}5-\mathrm{AdB}+\mathrm{NA}+ \\
\mathrm{NF}^{* *}\end{array}$ & $690,34 \mathrm{a}$ & $4,07 \mathrm{a}$ \\
\hline $6-\mathrm{AdB}+\mathrm{NF}$ & $570,76 \mathrm{bc}$ & $3,90 \mathrm{ab}$ \\
\hline $7-\mathrm{AdB}+\mathrm{Ur}+\mathrm{NA}$ & $668,54 \mathrm{a}$ & $4,10 \mathrm{a}$ \\
\hline $8-\mathrm{AdB}+\mathrm{NA}+\mathrm{Ur}$ & $680,02 \mathrm{a}$ & $4,02 \mathrm{a}$ \\
\hline $\mathrm{CV}(\%)$ & 19,87 & $15,98 \mathrm{a}$ \\
\hline
\end{tabular}

*Médias seguidas pela mesma letra na coluna não diferem estatisticamente pelo teste de Duncan ao nível de 5\% de probabilidade de erro.

** AdB: adubação de base. Ur: uréia. NF: nitrogênio foliar. NA: nitrato de amônio.

O N é o nutriente que mais onera o custo de produção nas lavouras de cereais de inverno. Todavia, o manejo com aplicações realizadas na base e em cobertura são fatores determinantes da produtividade da lavoura, assim, é interessante a adoção de práticas de manejo que proporcionem maior absorção de $\mathrm{N}$ do solo e, consequentemente, maior alocação do nutriente nos grãos (SCHUCH et al., 2000).

Com relação à produtividade de grãos, os tratamentos (adubação de base + nitrato de amônio + nitrogênio foliar) e (adubação de base + nitrato de amônio + ureia) mostram-se superiores aos demais. Segundo Zagonel et al. (2002) o nitrogênio é o principal nutriente requerido pelas gramíneas, proporcionando imediatamente um aumento de rendimento. Sua deficiência acarreta plantas de pequeno porte, desenvolvimento lento, poucos afilhos e baixa produtividade. Esta característica é percebida nos tratamentos, onde a utilização de nitrato de amônio mais adubação foliar proporcionou acréscimos de rendimento, possivelmente o nitrogênio requerido pela planta foi sendo disponibilizado de uma maneira gradual conforme se dava seu crescimento.

Ainda, segundo Rosa Filho (2012), quando aplicou-se N em cobertura no espigamento notou - se uma resposta clara no peso de mil sementes (PMS), passando de 30,6g para valores acima de $34 \mathrm{~g}$. Consequentemente, devido ao maior PMS pode - se constatar um maior rendimento de grãos.

O trigo é uma importante cultura do Sul do Brasil e principalmente para o Rio Grande do Sul, o cereal, ano a ano atravessa por dificuldades, tanto no setor comercial como por variações das condições climáticas. Em anos com ideais condições de ambiente a cultura é rentável para grande maioria dos produtores.

Os produtores necessitam além da produtividade que garante a lucratividade da lavoura atentar para a qualidade do grão do trigo. Este fator pode ser observado em parte pela massa hectolitrica ou PH. Conforme se pode observar pela comparação dos tratamentos houve magnitudes significativas, havendo superioridade para os tratamentos 4 e 8, porém, tais valores ainda estão abaixo dos índices ideais e mais remunerativos do mercado.

Uma importante característica que pode ser analisada é que a melhor resposta em produtividade não é vinculado ao tratamento com maior PH, tal circunstância segundo Mallmann et al. (1994), é que grãos com menor tamanho proporcionam um melhor ajuste no cilindro da balança, evitando espaços vazios e provocando maior aglutinação no momento de aferição da massa hectolítrica dos grãos. Frizzone et al. (1996), observaram redução na massa hectolítrica com o aumento da adubação 
nitrogenada, em que tal razão pode estar atribuída à maior competição entre os grãos por fotoassimilados, uma vez que o aumento da dose de nitrogênio aumentou o número de grãos por unidade de área.

Em relação à variável número de espigas por $\mathrm{m}^{-2}$ houve magnitudes significativas na comparação das médias. Os tratamentos 5, 7 e 8 mostram-se superiores na avaliação do caráter. Os tratamentos 1, 2 e 3 obtiveram a menor expressividade para número de afilhos. O baixo número de espigas nestes tratamentos, possivelmente está relacionado à disponibilização do $\mathrm{N}$, no tratamento 1 realizou-se somente aplicação na base da cultura, suponha-se que na fase de enchimento do grão a planta veio a sofrer com a deficiência do nutriente. Outra importante comparação é que independente da fonte ureia ou nitrato de amônio, a resposta da cultura seguiu o mesmo parâmetro para variável número de espigas por metro quadrado (RODRIGUES et al., 2002).

O número de afilhos por planta é uma importante variável que se relaciona indiretamente com o rendimento, principalmente se o número de afilhos seguir na maioria fértil. Uma importante característica a ser observada é que o parcelamento do nitrogênio se relaciona diretamente com número de afilhos por planta, pois o desenvolvimento destas estruturas primeiramente vegetativas e posteriormente reprodutivas, demandam maiores quantidades de nutrientes das plantas, na ocasião se a disponibilidade for adequada o crescimento e desenvolvimento vem a contribuir para elevação do rendimento de grãos, porém na baixa disponibilidade de nutrientes as plantas desenvolvem somente os estádios vegetativos dos afilhos, carregando energia da planta, quando há falta deste nutriente para o crescimento da espiga a planta acaba realizando o abortamento destas estruturas, e redistribuindo os nutrientes principalmente para crescimento e desenvolvimento da espiga da planta mãe, está por sua vez sendo a fonte principal da demanda energética pela planta.

Valério et al. (2009), ao concluírem seu trabalho afirmam que o melhor desempenho em produtividade é alcançado na seleção para reduzido número de afilhos, desde que, também considerada uma elevada massa de grãos, porém, é comum encontrar divergências sobre o caráter número de afilhos férteis. Dofing e Karlsson (1993 apud SILVA, 2010), relataram que as linhas unicolmo evidenciaram um rápido desenvolvimento de folhas e maturação mais precoce que linhas de afilhamento convencional. Por outro lado, as linhas unicolmo requerem elevada densidade de semeadura para expressarem ótimo rendimento de grãos. Já Common e Klinck (1981 apud SILVEIRA, 2010), afirmam que o fenótipo unicolmo seria limitado enquanto que o ideal seria um fenótipo com um colmo principal e dois ou três afilhos.

Neste âmbito, sugere-se um estudo mais aprofundado da identificação de estratégias eficientes em conhecer com base no padrão de afilhamento de cada cultivar, as técnicas que permitam incrementar o rendimento de grãos, pois, sendo o número de grãos e o peso médio fortemente determinado geneticamente em trigo, o número de afilhos férteis é o caráter mais fortemente influenciado pelas modificações do ambiente, e, portanto, o ajuste das técnicas de manejo em cultivares de reduzido e alto padrão de afilhamento serão determinantes em alavancar o caráter de rendimento de grãos.

Os resultados expressos neste trabalho revelam que os tratamentos com maior afilhamento, T5 (adubação de base + nitrato de amônio + nitrogênio foliar), T7 (adubação de base + ureia + nitrato de amônio) e T8 (adubação de base + nitrato de amônio + ureia) também expressam maior significância para rendimento, o que leva a uma relação indireta entre estes caracteres, que possivelmente a maior magnitude de rendimento destes tratamentos possam ser explicados pelo maior afilhamento destas plantas, contribuindo de maneira positiva para expressão destes caracteres.

Segundo Sangoi et al. (2008), a disponibilidade de N no início do ciclo é importante para que não ocorra a omissão de afilhos primários, fato observado em trigo. Por essa razão, a falta de $\mathrm{N}$ durante o ciclo reduz o número de afilhos por unidade de área emitida, o que reflete na redução do rendimento de grãos pela cultura.

\section{Conclusões}

REGET - V. 20, n. 1, jan.- abr. 2016, p.524-532 
A aplicação de $\mathrm{N}$ na forma de nitrato de amônio juntamente com suplementação via foliar resultou em um acréscimo no rendimento de grãos de 51,5\% em relação à testemunha.

A aplicação de nutrientes depende do objetivo do produtor, nos testes realizados para uma produção de massa de sementes os melhores resultados obtidos foi pela aplicação de nitrato de amônio + adubação foliar; ureia + nitrato de amônio e nitrato de amônio + ureia, já quando se leva em consideração o número de espigas $/ \mathrm{m}^{2}$ e afilhos por planta há superioridade em relação aos demais quando se utiliza: nitrato de amônio + adubação foliar, ureia + nitrato de amônio e nitrato de amônio + ureia.

Sendo obtido componentes de rendimento médios com magnitudes significativas verificadas pelo teste de Duncan a $5 \%$ de probabilidade de erro.

\section{Referências}

BIUDES, G.B.; CAMARGO, C. E. De O. Genótipos de trigo: características agronômicas em dois locais do estado de São Paulo. Bragantia, Campinas. v.68, n.4, p.873-884, 2009.

BRASIL. Ministério da Agricultura, Pecuária e Abastecimento. Regras para análise de sementes. Secretaria de Defesa Agropecuária. -Brasília, DF, 2009.

BREDEMEIER, C.; MUNDSTOCK, C.M.; BÜTTENBENDER, D. Efeito do tamanho das sementes de trigo no desenvolvimento inicial das plantas e no rendimento de grãos. Pesquisa agropecuária brasileira, Brasília. v. 36, n. 8, p. 1061-1068, ago. 2001.

CANTARELLA, H. Calagem e adubação do milho. In: BÜLL, L.T.; CANTARELLA, H. (Ed.). Cultura do milho: fatores que afetam a produtividade. Piracicaba: POTAFOS, 1993. p. 148-196.

COMPANHIA NACIONAL DE ABASTECIMENTO. Acompanhamento de safra brasileira: grãos, Quarto levantamento. Conab. Brasília, DF, 2012.

COODETEC IV Reunião da Comissão Brasileira de Pesquisa de Trigo e Triticale. Informações Técnicas para Trigo eTriticale - Safra 2012. Cascavel, PR, 2010.

EMPRESA BRASILEIRA DE PESQUISA AGROPECUÁRIA - EMBRAPA. Centro nacional de pesquisas de solos. Sistema brasileiro de classificação de solos. Rio de Janeiro, 1999.

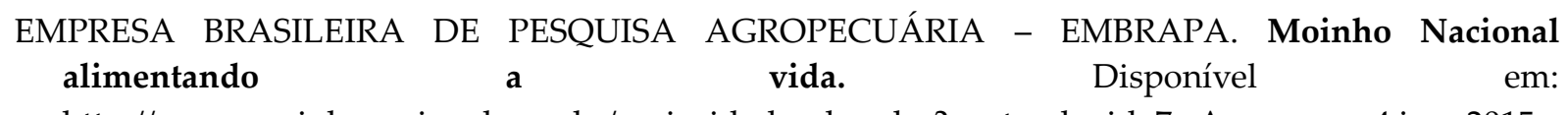
http://www.moinhonacional.com.br/curiosidades_ler.php?conteudo_id=7 . Acesso em: 4 jun. 2015.

EMPRESA BRASILEIRA DE PESQUISA AGROPECUÁRIA - EMBRAPA. Centro nacional de pesquisas em trigo. Notícia número 16/2011. Passo Fundo, RS, 2011.

FRIZZONE, J. A. et al. Efeito de diferentes níveis de irrigação e adubação nitrogenada sobre componentes de produtividade da cultura do trigo. Pesquisa Agropecuária Brasileira, Brasília. v.31, n.6, p.425-434, 1996.

MALLMANN, I. L. et al. Mecanismos de seleção aplicados sobre o caráter tamanho de grãos em populações segregantes de trigo. Pesquisa Agropecuária Brasileira, Brasília, v.29, n.3, p.427- 437, março de 1994.

MENEZES, M. J. T. Eficiência agronômica de fontes nitrogenadas e de associações de fertilizantes no processo de diferimento de Brachiaria brizanta cv. Marandu. 2004.113 f. Dissertação 
(Mestrado) - Escola Superior de Agricultura Luiz de Queiroz, Universidade de São Paulo, Piracicaba.

MORENO, J.A. Clima do Rio Grande do Sul. Secretaria da Agricultura do Rio Grande do Sul, Porto Alegre, 1961.

QUEIROZ, A. M.; SOUZA, C. H. E.; MACHADO, V. J.; LANA, R. M. Q.; KORNDORFER, G. H.; SILVA, A. A. Avaliação de diferentes fontes e doses de nitrogênio na adubação da cultura do milho (Zea mays L.). In: Revista Brasileira de Milho e Sorgo, v.10, n.3, p.257-266, 2011.

RODRIGUES, O. et al. Ministério da Agricultura Pecuária e Abastecimento - Mapa. Características fisiológicas associadas ao avanço no potencial de rendimento de grãos de trigo. Boletim de pesquisa e desenvolvimento 06 online. Empresa Brasileira de Pesquisa Agropecuária - Embrapa. Passo Fundo, RS, Dezembro de $2002 . \quad$ Disponível em: <http://www.cnpt.embrapa.br/biblio/p_bp06.htm>. Acesso em: 18 jun. 2012.

ROSA FILHO. O. Evolução Tecnológica da Produção de Trigo no Sul do Brasil 1977-2007. Disponível em:<www.orsementes.com.br/upload/artigo/52.pdf>. Acesso em: 01 jun. 2012.

SANGOI, L. et al. Disponibilidade de nitrogênio, sobrevivência e contribuição dos perfilhos ao rendimento de grãos do milho. Revista Brasileira de Ciência do Solo, Santa Maria, RS. v.35. p. 183-191, 2008.

SCHUCH, L. O. B. et al. Vigor de sementes de populações de aveia preta: II. Desempenho e utilização de nitrogênio. Scientia Agrícola, Piracicaba, v.57, n.1, p.121-127, jan - mar 2000.

SILVA, E. C.; SILVA, S. C.; BUZETTI, S.; TARSITANO, M. A. A.; LAZARINI, E. Análise econômica do estudo de níveis e épocas de aplicação de nitrogênio na cultura de milho no sistema plantio direto em solo de cerrados. In: Congresso Brasileiro de Administração Rural, 5, Goiânia, 2001. Anais... Goiânia, ABAR, 2001. CD-ROM

SILVA, J. A. G. Da. Expressão do caráter número de afilhos sobre o rendimento de grãos e seus componentes em trigos uni e multicolmos com base em modificações das técnicas de manejo. Comunicado técnico, 2010.

SILVEIRA, G. Da. Efeito da densidade de semeadura e potencial de afilhamento sobre a adaptabilidade e estabilidade em trigo. Bragantia, Campinas, v.69 n.1,2010.

SOCIEDADE BRASILEIRA DE CIÊNCIA DO SOLO. Comissão de química e fertilidade do solo. Manual de adubação e calagem para os Estados do Rio Grande do Sul e Santa Catarina. - 10. Ed. Porto Alegre,2004.

VALÉRIO, I. P. et al. Seleção efetiva para o caráter número de afilhos em populações segregantes de trigo. Bragantia, Campinas,v.68, n.4, p.885-899, 2009.

YAMADA, T. Adubação nitrogenada do milho: quanto, como e quando aplicar. Piracicaba: Potafos, 1996. 5 p. (Informações Agronômicas, 74.)

ZAGONEL J. et al. Doses de nitrogênio e densidades de plantas com e sem um regulador de crescimento afetando o trigo, cultivar or-1.Ciência Rural, Santa Maria, v.32, n.1, p.25-29,2002.R, J. Generalized linear models. 2. ed. London: Chapman and Hall, 1989. 